\title{
A novel neurodegenerative disease characterised by posterior column ataxia and pyramidal tract involvement maps to chromosome 8p12-8q12.1
}

\author{
P N Valdmanis, A A Simões Lopes, F Gros-Louis, J D Stewart, G A Rouleau, N Dupré
}

J Med Genet 2004;41:634-639. doi: 10.1136/jimg.2004.019711

T he recent barrage of linkage assignments and gene discoveries has confirmed the clinical and genetic heterogeneity of ataxic diseases. They all share the prototypic feature of difficulty in walking though many additionally present dysarthria, spasticity, retinopathy, and other neurological symptoms. ${ }^{1}$ Broad subgroups of ataxias and related diseases exist including spinocerebellar and spastic ataxias, each with their own characteristic features.

The clinical and genetic heterogeneity of ataxias is best represented by the autosomal dominant cerebellar ataxias (ADCAs). Indeed, a minimum of 22 loci have been discovered, including those for the spinocerebellar ataxias (SCA1-8, SCA10-17, SCA19, SCA21, and SCA22), ${ }^{2-8}$ the episodic ataxias $\mathrm{EAl}^{9}$ and $\mathrm{EA} 2,{ }^{10}$ and the complex disorder, dentatorubropallidoluysian atrophy (DRPLA). ${ }^{11}$ Similarly, Friedreich's ataxia (FRDA) is an autosomal recessive disease which affects the spinocerebellar and pyramidal tracts. Symptoms are typically noticed before 20 years of age and include dysarthria, nystagmus, areflexia, and a positive Babinski sign. ${ }^{12}$ Hereditary spastic ataxia (HSA) is characterised by retinopathy, muscle wasting, nystagmus, and dysarthria. ${ }^{13}$ Spastic ataxia (SAX1) is the first described dominant form, ${ }^{14}$ while the autosomal recessive spastic ataxia of Charlevoix-Saguenay (ARSACS) is one of a number of recessive forms. ${ }^{15}$ All told, the loci responsible for a significant proportion of hereditary causes of ataxias still have not been elucidated. ${ }^{16}$

A large amount of heterogeneity is also observed within the hereditary neuropathies. These include the hereditary sensory neuropathies (HSNs) ${ }^{17}$ and the more common hereditary motor and sensory neuropathies (HMSNs). ${ }^{18}$ Sensory ataxia is not present in the HSNs ${ }^{19}$ since they affect mainly the unmyelinated and small myelinated nerve fibres, nor is it present in the HMSNs, where sensory symptoms are seldom the presenting complaint. A few rare families have been described with a hereditary sensory-motor neuropathy associated with ataxia (SMNA) of neuropathic origin. ${ }^{20-22}$ These can include both central and peripheral nervous system involvement and neurogenic muscle atrophy. ${ }^{23}$ Similarly, a combination of ataxia originating in the cerebellum with signs of peripheral neuropathy has been reported. ${ }^{24-26}$ Neuropathies that affect large myelinated peripheral nerve fibres or their cell bodies located in the dorsal root ganglia can induce a sensory ataxia. Both preganglionic and postganglionic sensory nerve fibres are implicated in these forms of sensory ataxias.

Here we report an eastern Canadian family from New Brunswick with Anglo-Saxon ancestry. The family has a novel neurodegenerative disease characterised by sensory (posterior column) ataxia and variable pyramidal weakness but with no overt signs of peripheral sensory or motor neuropathy. This suggests a pure sensory ataxia caused primarily by involvement of the preganglionic sensory nerve

\section{Key points}

- The ataxias and hereditary sensory neuropathies (HSNs) are clinically and genetically heterogeneous disorders.

- A Canadian family from New Brunswick, of AngloSaxon origin, has been identified whose affected members do not display classic signs of sensory neuropathy or spinocerebellar ataxia but who nonetheless have a debilitating sensory (posterior column) ataxia occasionally coupled with pyramidal weakness; as a result, we entitle this disease autosomal dominant sensory ataxia (ADSA).

- Ten affected patients from a single pedigree were subjected to clinical characterisation and linkage analysis. A genome scan performed on the family yielded a locus on chromosome 8 with a maximum LOD score of 4.90 for marker D8S1791. This locus has been designated as sensory ataxia 1 (SNAX1) and maps to a $9.1 \mathrm{cM}$ chromosomal interval from $8 \mathrm{p} 12$ to $8 q 12.1$. The candidate genes fibroblast growth factor receptor 1 and glutathione reductase were screened without detection of a coding variation.

fibres (posterior column). To describe this distinct diagnostic entity, we propose the term autosomal dominant sensory ataxia (ADSA).

\section{METHODS}

\section{Clinical findings}

This family has 10 affected living members including six females and four males (fig l, table 1). This progressive disease does not appear to influence the overall lifespan of those affected. The typical age of onset is in the third and fourth decades ranging from 28 to 55 years, while there is no definite evidence of genetic anticipation. Most patients initially experience a difficulty in gait although some also report instability, especially in the dark. Deep tendon reflexes are usually diminished in the arms and are altogether absent

Abbreviations: $A D C A$, autosomal dominant cerebellar ataxia; $A D S A$, autosomal dominant sensory ataxia; ARSACS, autosomal recessive spastic ataxia of Charlevoix-Saguenay; C-MAPs, compound motor nerve action potentials; DRPLA, dentatorubropallidoluysian atrophy; FGFR 1, fibroblast growth factor receptor 1; FRDA, Friedreich's ataxia; GSR, glutathione reductase; HAS, hereditary spastic ataxia; HMSN, hereditary motor and sensory neuropathy; HSN, hereditary sensory neuropathy; $M R I$, magnetic resonance imaging; SAX1, spastic ataxia; SMNA, sensory-motor neuropathy associated with ataxia; SNAPs, sensory nerve action potentials; SNAX1, sensory ataxia 1 
Table 1 Clinical findings of ten confirmed affected cases

\begin{tabular}{|c|c|c|c|c|c|c|c|c|c|c|c|}
\hline \multirow[b]{2}{*}{ Patient } & \multirow{2}{*}{$\begin{array}{l}\text { Age at } \\
\text { onset }\end{array}$} & \multirow{2}{*}{$\begin{array}{l}\text { Age at } \\
\text { eval. }\end{array}$} & \multicolumn{2}{|l|}{ Reflexes } & \multirow{2}{*}{$\begin{array}{l}\text { Plantar } \\
\text { response }\end{array}$} & \multicolumn{2}{|c|}{$\begin{array}{l}\text { Distal sensory loss } \\
(\mathrm{P}+\mathrm{T})\end{array}$} & \multicolumn{2}{|c|}{$\begin{array}{l}\text { Distal sensory loss } \\
\text { (Pr+V) }\end{array}$} & \multirow[b]{2}{*}{ Ataxia } & \multirow[b]{2}{*}{ Additional information } \\
\hline & & & Arms & Legs & & Arms & Legs & Arms & Legs & & \\
\hline $\mathrm{IV}: 4$ & $?$ & 29 & $\downarrow \downarrow$ & 0 & Flexor & + & + & None & None & None & \\
\hline $\mathrm{IV}: 8$ & $?$ & 34 & $\downarrow \downarrow$ & 0 & Flexor & None & None & None & None & None & \\
\hline IV:1 & 35 & 38 & $\downarrow \downarrow$ & 0 & Flexor & + & ++ & None & + & None & \\
\hline IV:6 & 28 & 42 & $\downarrow \downarrow$ & 0 & Extensor & + & ++ & None & ++ & ++ & \\
\hline III:5 & 45 & 55 & 0 & 0 & $\begin{array}{l}\text { Triple } \\
\text { flexion }\end{array}$ & ++ & +++ & + & +++ & NA & $\begin{array}{l}\text { Jerky saccades, paraplegia, } \\
\text { normal MRI and NCS }\end{array}$ \\
\hline III:3 & 35 & 58 & $\downarrow \downarrow$ & 0 & Flexor & + & ++ & None & +++ & ++ & Normal MRI and NCS \\
\hline III:9 & $?$ & 61 & $\downarrow \downarrow$ & 0 & Flexor & + & ++ & None & + & + & \\
\hline III:7 & 55 & 65 & 0 & 0 & Flexor & + & ++ & + & +++ & ++ & Normal MRI and NCS \\
\hline III: 14 & $?$ & 65 & Normal & & Flexor & None & + & None & +++ & + & Normal MRI \\
\hline III: 12 & 50 & 67 & $\downarrow \downarrow$ & 0 & Extensor & + & ++ & None & +++ & +++ & Jerky saccades, normal MRI and NCS \\
\hline
\end{tabular}

$\downarrow \downarrow$, diminished; 0 , abolished; $(+)$, mild; $(++)$, moderate; $(+++)$, severe; EMG, electromyography; eval., evaluation; MRI, magnetic resonance imaging; NA, not applicable; NCS, nerve conduction studies; P, pain; Pr, proprioception; SSEP, somatosensory evoked potentials; T, temperature; V, vibration.

in the legs. Some affected subjects have extensor plantar responses and weakness of the lower extremities. Sensation to all modalities (touch, pain, temperature, proprioception, and vibration) is invariably decreased distally, but more so in the legs than in the arms. There are never significant bruises or foot ulcerations. Autonomic dysfunction, such as sphincter disturbance or orthostatic hypotension, is not present. Apart from mild jerky pursuit abnormalities on eye movement testing in a few subjects, there are no signs of cerebellar dysfunction such as dysmetria or dysarthria. Brain and spine magnetic resonance imaging (MRI) are normal in all five individuals tested. Similarly, compound motor nerve action potentials (C-MAPs) and sensory nerve action potentials (SNAPs) are normal. To illustrate the variation in phenotypic expression, the clinical evaluation of four affected members conducted by one of the authors (ND) is described here in more detail.

\section{Case 1 (III:5)}

This subject is the most severely affected. His symptoms began around 45 years of age as progressive gait difficulty. By the age of 49 he needed a walker, and a year later he was wheelchair bound. He was examined at the age of 55. Cognitive function was normal. Cranial nerve examination was normal except for some mild jerkiness of ocular pursuit, while his saccadic eye movements were normal. There was neither nystagmus nor dysarthria. Motor examination was normal in the upper limbs, while the lower limbs showed a

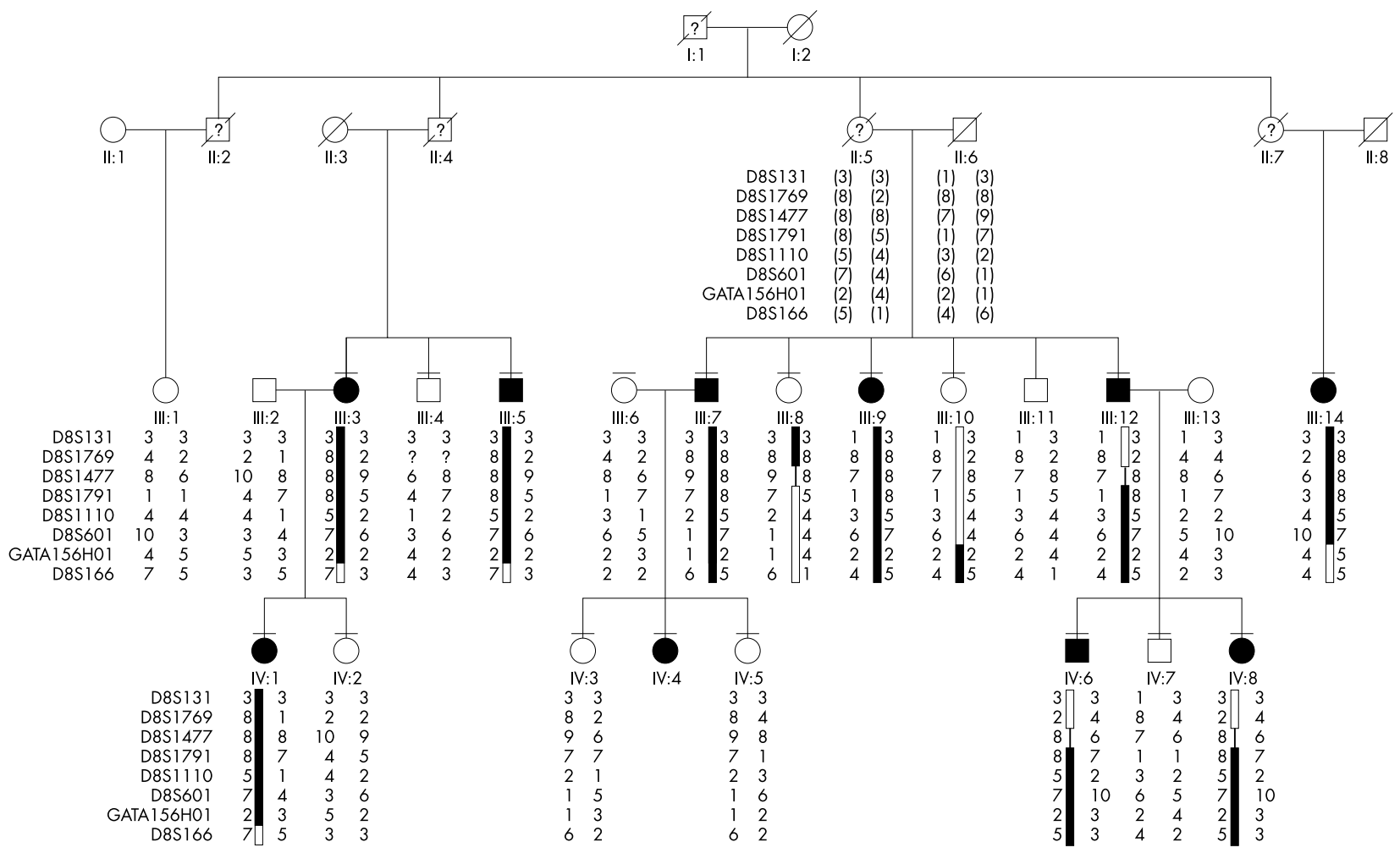

Figure 1 The chromosome 8p12-8q12.1 haplotype for collected individuals in this study's family. Males appear as squares and females as circles. Black and white symbols represent affected and unaffected individuals, respectively, while a question mark indicates an individual affected by hearsay. A diagonal line denotes a deceased individual. For disease haplotypes, a thick black bar indicates the area on the haplotype associated with the disease, while a thin black bar indicates a potentially associated area. Alleles in parentheses are inferred. Markers D8S1769 and GATA156H01 were determined to be boundaries of the $9.1 \mathrm{cM}$ segregating region when taking into account the recombinations in individuals III:12 and III:14. 
complete flaccid paraplegia. Despite this, there was no significant muscle atrophy. Reflexes were absent in the limbs. Plantar stimulation elicited a triple-flexion reflex. Sensory examination revealed moderately diminished perception of all main modalities distal to the elbows in the upper limbs. In the lower limbs, all modalities were severely diminished distal to the knees. There was no dysmetria on the finger-to-nose test. There was no sphincter disturbance. Electrophysiological studies showed that C-MAPs and SNAPs were both normal. Of particular note, the left sural nerve SNAP was normal despite severely diminished sensation in the leg. The needle electromyographic examinations of distal and proximal muscles were normal. Interestingly, somatosensory evoked responses from upper limb stimulation showed a prolonged latency, while evoked responses from lower limb stimulation were unobtainable. The combination of normal sensory nerve conductions and abnormal evoked responses clearly indicates preganglionic (posterior column) involvement. Cerebrospinal fluid examination was normal, with no oligoclonal bands. Similarly, right sural nerve biopsy and left deltoid muscle biopsy were normal. Levels of vitamin B12, homocysteine, vitamin E, $\beta$-lipoprotein, and very long chain fatty acids were all normal. Finally, brain and spine MRI were also normal.

\section{Case 2 (III:7)}

This patient developed progressive gait difficulty, especially in the dark, at around 55 years of age. He needed a cane at the age of 58 and was examined at 65. Cognitive function, cranial nerve examination and ocular pursuit and saccades were all normal. No dysarthria was observed. Motor examination was normal in the limbs, but all reflexes were absent and plantar responses were flexor. Sensory examination revealed a mildly diminished perception of all modalities distal to the elbows. In the legs, all modalities were severely diminished distal to the knees. No dysmetria was seen on the finger-to-nose test. The gait was quite abnormal with a strikingly wide base and an inability of the patient to perform more than two steps on his own. The patient developed marked instability on closing his eyes indicating a positive Romberg sign.

Case 3 (III: 12)

This patient developed progressive gait difficulty around the age of 50. By 60, he required a cane, and was examined at the age of 67. Cognitive function was normal. Apart from some mild jerkiness of his ocular pursuit, his cranial nerve examination and saccadic eye movements were normal. Nystagmus and dysarthria were absent. Muscle tone and strength were normal. Reflexes were diminished in the arms and absent in the legs. The plantar responses were extensor bilaterally. Sensory examination revealed a mildly diminished perception of pain and temperature distal to the elbows while vibration and proprioception were normal. In the legs, pain and temperature perception were severely diminished distal to the knees while proprioception and vibration were absent at the big toes. Vibration was also absent at the ankles. The heel-to-shin test was very impaired due to proprioceptive loss, although there was no dysmetria on the finger-to-nose test. The gait was quite abnormal with a strikingly wide base. The patient was unable to take more than two steps on his own and had a positive Romberg sign. Electrophysiological studies were performed by LW: C-MAPs and SNAPs were normal in the arms and legs. Needle examinations of distal and proximal limb muscles were normal.

Case 4 (III:3)

This patient's symptoms arose around 35 years of age as progressive gait difficulty, particularly in the dark. She was examined at the age of 58. Cognitive function and the cranial nerve examination were normal, including ocular saccades and smooth pursuit. There was no nystagmus or dysarthria. Motor examination was normal in the limbs, but all tendon reflexes were absent and plantar responses were flexor. The perception of pain and temperature was slightly decreased distal to the elbows while vibration and proprioception were normal in the hands. However, in the legs, pain and temperature sensations were severely diminished distal to the knees and proprioception and vibration were absent at the big toes. Vibration was also absent at the ankles. There was no dysmetria on the finger-to-nose test; however, the heel-to-shin test was impaired due to proprioceptive loss. An abnormal gait with a wide base was observed. A Romberg sign was also present.

\section{Pedigree and DNA analysis}

Analysis of the pedigree reveals an autosomal dominant mode of inheritance given the evidence of male-to-male transmission and a penetrance that correlates with the age of the patient (table 1). Upon receipt of informed consent, blood samples were obtained from 21 individuals, including nine affected members in two generations of the family, as approved by the Ethics Committee of the McGill University Health Center. DNA was extracted from the peripheral blood by standard methods. ${ }^{27}$ Ten samples comprised of eight affected individuals and two normal spouses were subjected to a genome-wide scan. A total of 400 markers spanning all chromosomes at approximately $10 \mathrm{cM}$ intervals were typed. Subsequent marker positions were determined using the Marshfield genetic map (Marshfield Center for Medical Genetics). Primers for each marker were generated from their respective UCSC genome browser sequence (UCSC Human Genome Project Working Draft). Alleles were visualised by incorporating $\left[{ }^{35} \mathrm{~S}\right] \mathrm{dATP}$ in PCR products and separated on a $6 \%$ polyacrylamide gel. The size and frequency of alleles were based on values from the Fondation Jean Dausset - CEPH database and compared to an M13mpl8 sequence ladder. Two-point and multipoint linkage analyses were conducted using the MLINK and LINKMAP programs respectively within the LINKAGE software package. ${ }^{28}$ LOD score calculations were based on a disease frequency estimated at 1 in 10000 , a penetrance of $90 \%$, and equal male-female recombination frequencies.

\section{RESULTS}

Initially, genetic testing was performed on the proband (case 1 above) to exclude SCAl, SCA6, and SCA7. The subsequent

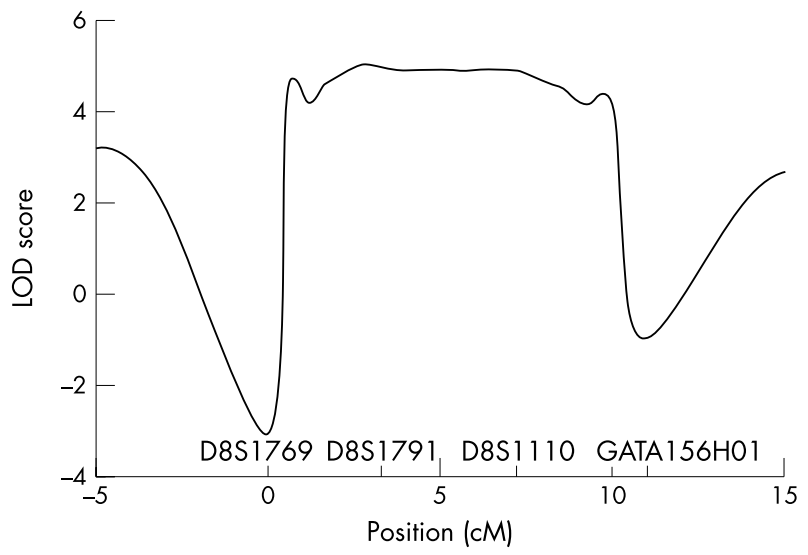

Figure 2 Multipoint linkage analysis of the ADSA candidate region on chromosome 8. Markers D8S1769 and GATA156H01 flank the linked region. 
Table 2 Two-point LOD scores for markers on chromosome 8

\begin{tabular}{|c|c|c|c|c|c|c|c|c|c|c|}
\hline \multirow[b]{2}{*}{ Marker } & \multirow[b]{2}{*}{ Position, cM } & \multicolumn{7}{|c|}{ Recombination fraction $(\theta)$} & \multirow[b]{2}{*}{$Z_{\max }$} & \multirow[b]{2}{*}{$\theta_{\max }$} \\
\hline & & 0.00 & 0.01 & 0.05 & 0.10 & 0.20 & 0.30 & 0.40 & & \\
\hline D8S131 & 54.98 & 0.65 & 0.64 & 0.59 & 0.54 & 0.42 & 0.30 & 0.16 & 0.65 & 0.00 \\
\hline D8S1769 & 60.34 & -4.16 & 0.97 & 1.53 & 1.61 & 1.35 & 0.89 & 0.39 & 1.61 & 0.09 \\
\hline D8S1477 & 60.34 & 2.24 & 2.21 & 2.05 & 1.85 & 1.43 & 0.98 & 0.51 & 2.24 & 0.00 \\
\hline D8S1791 & 63.00 & 4.90 & 4.81 & 4.45 & 3.98 & 2.98 & 1.88 & 0.76 & 4.90 & 0.00 \\
\hline D8S1110 & 67.27 & 4.74 & 4.66 & 4.32 & 3.88 & 2.94 & 1.92 & 0.84 & 4.74 & 0.00 \\
\hline D8S601 & 67.27 & 4.76 & 4.68 & 4.35 & 3.91 & 2.98 & 1.96 & 0.88 & 4.76 & 0.00 \\
\hline GATA156HOI & 69.40 & -1.98 & 0.36 & 0.97 & 1.13 & 1.03 & 0.72 & 0.31 & 1.14 & 0.12 \\
\hline D8S166 & 71.00 & -1.32 & 1.18 & 1.74 & 1.81 & 1.54 & 1.05 & 0.49 & 1.81 & 0.10 \\
\hline
\end{tabular}

genome scan yielded 12 suggestively linked markers based on a LOD score of between 1.5 and 2.0 including two adjacent markers on chromosome 8 . No markers yielded an LOD score greater than 2. Each of the 12 suggestive loci was further examined by genotyping other affected and unaffected individuals for nearby markers. This allowed more informative LOD score calculations and haplotype analysis, which confirmed the locus on chromosome 8 (table 2). Significant LOD scores of 4.74 and $4.76(\theta=0)$ were obtained at markers D8S1110 and D8S601, respectively, while the maximum LOD score was $4.90 \quad(\theta=0)$ at marker D8S1791. Multipoint analysis of the area, increasing the LOD score to 5.07, is shown in fig 2. A disease-related haplotype was constructed such that it incorporated the minimum number of recombinants. Individual III:12 defines the upper recombination boundary between markers D8S1769 and D8S1477, while individual III:14 delimits the lower boundary between markers D8S601 and GATA156H01. The region was narrowed to a gene-rich interval of $9.1 \mathrm{cM}(24.9 \mathrm{Mb})$, between $8 \mathrm{pl} 2$ and 8q12.1. The HUGO Gene Nomenclature Committee approved the name sensory ataxia 1 (SNAX1) for this locus.

Based on the UCSC Human Genome Project Working Draft Database accessed in July 2003, 21 reviewed and 67 predicted genes fell within the region; however, two particular genes stood out. The fibroblast growth factor receptor l (FGFRl) immediately became an exciting candidate given its implication in neuronal development and organisation. ${ }^{29}$ Furthermore, it is mechanistically related to the fibroblast growth factor 14 which recently was found to be responsible for an autosomal dominant cerebellar ataxia. ${ }^{30}$ Similarly, the gene encoding glutathione reductase (GSR), which restores active glutathione levels, is located in the surrounding region. Glutathione deficiency has been associated with Friedrich's ataxia and a host of other neurodegenerative disorders. ${ }^{31} 32$ We sequenced the 19 exons of FGFRl and 13 exons of GSR extending at least 50 base pairs into introns upstream and downstream from each exon without detecting any significant variations. Primer sequences are available upon request.

\section{DISCUSSION}

This distinct neurodegenerative disorder is characterised by a posterior column ataxia and pyramidal tract involvement. It shares certain common features with sensory neuropathies, including loss of sensation and reflexes in the limbs and a delay in somatosensory evoked potentials. However, unlike in HSNs and HMSNs, nerve conduction studies and nerve biopsies are normal. This precludes the postganglionic sensory nerve fibre from pathogenic involvement and points to the preganglionic sensory nerve fibre (posterior column). The effects are thus more central than peripheral in nature. Importantly, the most severe feature of ADSA is gait ataxia, which is rare among the HSNs. Biemond's ataxia is an autosomal dominant posterior column ataxia characterised by a reduction of sensory action potentials on nerve conduction testing accompanied by ataxia with cerebellar atrophy, ${ }^{33}$ features which clearly differentiate it from ADSA. That ADSA affects sensory instead of spinocerebellar pathways and the cerebellum also sets it apart from the SCAs. ${ }^{1}$ It is the loss of proprioception and not of movement coordination that accounts for the ataxia. Genetic analysis has excluded diseases of a similar nature and mapped ADSA to a novel locus on chromosome $8 \mathrm{pl2}-8 \mathrm{q} 12.1$. The region corresponds to an interval of approximately $9.1 \mathrm{cM}$ between markers D8S1769 and GATA156H0l and contains 21 reviewed and 67 predicted genes. Currently, only one family has been identified in a geographically isolated region making it difficult to obtain more detailed clinical testing. Naturally, the search for other families with ADSA will continue. This will allow a better appreciation of the phenotype and further narrow the critical region in the event that an informative recombinant is found.

Recently, a flood of genetic information has provided insight into the mechanisms and dysfunctions leading to the various forms of ataxias. Of the 12 genes responsible for various SCAs, ten are defective due to trinucleotide repeat expansions. $^{34}$ The length of the repeat becomes more pronounced with each successive generation leading to an earlier age of onset of the disease and therefore genetic anticipation. This has been shown to occur in the gene for SCAl, ataxin-1, in which the number of CAG repeats encoding glutamine amino acids is directly correlated with the severity of the disease and its age of onset. ${ }^{16}$ Although the limited number of generations collected may mask its presence, there is no direct evidence of anticipation through this family, suggesting that a triplet repeat expansion is unlikely to be implicated. When queried, the compiled genomic sequence from UCSC revealed no lengthy CAG repeats in the candidate region.

Another major theme for pathogenesis, seen in autosomal recessive ataxias, involves genes implicated in metabolic processes. The pathways involved usually provide hints to the genes implicated. Exemplary of this, a mutation in the microsomal triglyceride transfer protein is responsible for abetalipoproteinemia which presents with ataxia. ${ }^{35}$ Thus, a gene in the region that displays great promise is one that shares homology with tetrahydrofolate synthase (Celera database, hCG1647345). The folate biosynthesis pathway depends on vitamin B12, and the two have both been linked to neurodegenerative diseases. Gait disturbance can regularly be seen as an initial complaint of vitamin B12 deficiency, with or without haematological defects such as megaloblastic anaemia. ${ }^{36}$ Many of the phenotypic features of ADSA patients are similar to those with vitamin B12 deficiency. ${ }^{37} 38$

Incorporating this information, other genes in the chromosome 8 region for ADSA will also be screened in an order relative to their homology or commonality to genes previously discovered for ataxias and sensory neuropathies. Naturally, priority will be given to genes highly expressed in 
the central nervous system because of the distribution of the sensory deficits evident in this family.

One other locus related to a neurodegenerative disease is present in the same region and thus particular attention must be paid to it. This locus is for the spastic paraplegia SPG5A which extends from 8q11.1 to 8q21.2 and shares one linked marker (D8S601). ${ }^{39}$ However, the disease is a recessive one and presents a separate phenotype so the likelihood that the same gene is involved in both diseases is slim. Likewise, the gene for ataxia with vitamin E deficiency (AVED) was excluded because it lies outside the candidate region at $8 \mathrm{q} 12.3$ and vitamin E levels were not diminished. ${ }^{40}$

Identification of the gene involved in ADSA would aid in the genetic screening and counselling of subjects. It would further provide an understanding of the pathway(s) involved in a sensory ataxia, show any mechanistic differences between this disease and the SCAs, and perhaps provide a link between sensory ataxia and the peripheral neuropathies. The identification and characterisation of ADSA offers a unique perspective of the pathophysiology of ataxic diseases on the whole.

\section{ACKNOWLEDGEMENTS}

We are greatly indebted to the family involved for their participation. We would also like to thank Doctor Lyle Weston (Moncton Hospital, New Brunswick, Canada) for referring the proband to us and Doctor Ted Roberts (University of Alberta, Canada) for the investigation of another patient. The assistance of Drs T Hudson and A Verner, of the McGill University and Genome Quebec Innovation Center, is much appreciated.

\section{ELECTRONIC-DATABASE INFORMATION}

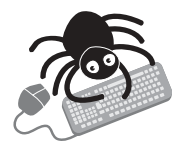

Accession numbers and URLs for data in this article are as follows: Celera Discovery System, http:// www.celeradiscoverysystem.com/; Center for Medical Genetics, Marshfield Medical Research Foundation, http://research.marshfieldclinic.org/genetics/; Fondation Jean Dausset - CEPH, http:// www.cephb.fr/; The Genome Database, http:// www.gdb.org/; HUGO Gene Nomenclature Committee, http://www.gene.ucl.ac.uk/ nomenclature/; Online Mendelian Inheritance in Man (OMIM), http://www.ncbi.nlm.nih.gov/Omim/; UCSC Human Genome Project Working Draft ("Golden Path"), http://genome.ucsc.edu

\section{Authors' affiliations \\ P N Valdmanis, A A Simões Lopes, F Gros-Louis, G A Rouleau, N Dupré, McGill University Health Centre Research Institute and the Centre for Research in Neurosciences, 1650 Cedar Ave, Montreal, QC, Canada H3G 1A4 \\ J D Stewart, Montreal Neurological Hospital and Institute, and the Department of Neurology and Neurosurgery, McGill University, 3801 University St, Montreal, QC, Canada H3A 2B4 N Dupré, Département des Sciences Neurologiques, Centre de Recherche, Centre Hospitalier Affilié, Hôpital de l'Enfant-Jésus, Laval University, 1401, 18th St, Québec City, QC, Canada G1J 1 Z4}

The Canadian Institute of Health Research (CIHR) funded this study. FG-L and ND are supported by CIHR, while PNV is supported by the Natural Sciences and Engineering Research Council of Canada.

Conflict of interest: none declared.

Correspondence to: Dr Nicolas Dupré, McGill University Health Centre Research Institute and the Centre for Research in Neurosciences, L7120, 1650 Cedar Ave, Montreal, QC, Canada H3G 1A4; nicolas.dupre@mail.mcgill.ca

Revised version received 30 March 2004

Accepted for publication 1 April 2004

\section{REFERENCES}

1 Harding AE. Clinical features and classification of the inherited ataxias. In: Harding AE, Deufel T, eds. Advances in neurology. New York: Raven Press, 1993:1-14.

2 Paulson $\mathrm{H}$, Ammache Z. Ataxia and hereditary disorders. Neurol Clin $2001 ; 19: 759-82$, viii.

3 Knight MA, Kennerson ML, Anney RJ, Matsuura T, Nicholson GA, SalimiTari P, Gardner RJ, Storey E, Forrest SM. Spinocerebellar ataxia type 15 (sca15) maps to 3p24.2-3pter: exclusion of the ITPRI gene, the human orthologue of an ataxic mouse mutant. Neurobiol Dis 2003;13:147-57.

4 Miyoshi Y, Yamada T, Tanimura M, Taniwaki T, Arakawa K, Ohyagi Y, Furuya H, Yamamoto K, Sakai K, Sasazuki T, Kira J. A novel autosomal dominant spinocerebellar ataxia (SCA16) linked to chromosome 8q22.124.1. Neurology 2001;57:96-100.

5 Koide R, Kobayashi S, Shimohata T, Ikeuchi T, Maruyama M, Saito M, Yamada M, Takahashi H, Tsuji S. A neurological disease caused by an expanded CAG trinucleotide repeat in the TATA-binding protein gene: a new polyglutamine disease? Hum Mol Genet 1999:8:2047-53.

6 Verbeek DS, Schelhaas JH, Ippel EF, Beemer FA, Pearson PL, Sinke RJ. Identification of a novel SCA locus (SCA19) in a Dutch autosomal dominant cerebellar ataxia family on chromosome region 1p21-q21. Hum Genet 2002;111:388-93.

7 Vuillaume I, Devos D, Schraen-Maschke S, Dina C, Lemainque A, Vasseur F, Bocquillon G, Devos P, Kocinski C, Marzys C, Destee A, Sablonniere B. A new locus for spinocerebellar ataxia (SCA21) maps to chromosome 7p21.3p15.1. Ann Neurol 2002;52:666-70.

8 Chung MY, LU YC, Cheng NC, Soong BW. A novel autosomal dominant spinocerebellar ataxia (SCA22) linked to chromosome 1p21-q23. Brain 2003; 126:1293-9.

9 Litt M, Kramer P, Browne D, Gancher S, Brunt ER, Root D, Phromchotikul T, Dubay CJ, Nutt J. A gene for episodic ataxia/myokymia maps to chromosome 12p13. Am J Hum Genet 1994:55:702-9.

10 von Brederlow B, Hahn AF, Koopman WJ, Ebers GC, Bulman DE. Mapping the gene for acetazolamide responsive hereditary paryoxysmal cerebellar ataxia to chromosome 19p. Hum Mol Genet 1995;4:279-84.

11 Takano T, Yamanouchi Y, Nagafuchi S, Yamada M. Assignment of the dentatorubral and pallidoluysian atrophy (DRPLA) gene to $12 \mathrm{p} 13.31$ by fluorescence in situ hybridization. Genomics 1996;32:171-2.

12 Harding AE. Friedreich's ataxia: a clinical and genetic study of 90 families with an analysis of early diagnostic criteria and intrafamilial clustering of clinical features. Brain 1981;104:589-620.

13 Mahloudii M. Hereditary spastic ataxia simulating disseminated sclerosis. J Neurol Neurosurg Psychiatry 1963;26:511-3.

14 Meijer IA, Hand CK, Grewal KK, Stefanelli MG, Ives EJ, Rouleau GA. A locus for autosomal dominant hereditary spastic ataxia, SAX1, maps to chromosome 12pl3. Am J Hum Genet 2002:70:763-9.

15 Bouchard J, Barbeau A, Bouchard R, Bouchard R. Autosomal recessive spastic ataxia of Charlevoix-Saguenay. Canad J Neurol Sci 1978;5:61-9.

16 Moseley ML, Benzow KA, Schut L, Bird TD, Gomez CM, Barkhaus PE, Blindaver KA, Labuda M, Pandolfo M, Koob MD, Ranum LP. Incidence of dominant spinocerebellar and Friedreich triplet repeats among 361 ataxia families. Neurology 1998;51:1666-71

17 Nicholson GA, Dawkins JL, Blair IP, Kennerson ML, Gordon MJ, Cherryson AK, Nash J, Bananis T. The gene for hereditary sensory neuropathy type I (HSN-I) maps to chromosome 9q22.1-q22.3. Nat Genet 1996; 13:101-4.

18 Dyck PJ, Chance P, Leno R, Carney J. Hereditary motor and sensory neuropathies. In: Dyck PJ, Thomas P, Griffin J, eds. Peripheral neuropathy. Philadelphia: W.B. Saunders, 1993:1094-136.

19 Dyck PJ. Neuronal atrophy and degeneration predominantly affecting peripheral sensory and autonomic neurons. In: Dyck PJ, Thomas PK, Griffin J, eds. Peripheral neuropathy. Philadelphia: W.B. Saunders, 1993:1065-93.

20 van Dijk GW, Wokke JH, Oey PL, Franssen H, Ippel PF, Veldman H. A new variant of sensory ataxic neuropathy with autosomal dominant inheritance. Brain 1995; 118:1557-63.

21 Nogues M, Leiguarda R, Sevlever G, Garcia H. [Chronic hereditary ataxic polyneuropathy]. Medicina (B Aires) 2000;60:316-20

22 Kyriakides T, Georgio DM, Zamba E, Kyriakou K, Christodoulou K, Cyprus N, Thomas PK. A novel form of sensory ataxic neuropathy of autosomal recessive inheritance. Neurology 2001;56:A324.

23 Brkanac Z, Fernandez M, Matsushita M, Lipe H, Wolff J, Bird TD, Raskind WH. Autosomal dominant sensory/motor neuropathy with ataxia (SMNA): linkage to chromosome 7q22-q32. Am J Med Genet 2002;114:450-7.

24 Flanigan K, Gardner K, Alderson K, Galster B, Otterud B, Leppert MF, Kaplan C, Ptacek L. Autosomal dominant spinocerebellar ataxia with sensory axonal neuropathy (SCA4): clinical description and genetic localization to chromosome 16q22.1. Am J Hum Genet 1996:59:392-9.

25 Bomont P, Watanabe M, Gershoni-Barush R, Shizuka M, Tanaka M, Sugano J, Guiraud-Chaumeil C, Koenig M. Homozygosity mapping of spinocerebellar ataxia with cerebellar atrophy and peripheral neuropathy to 9q33-34, and with hearing impairment and optic atrophy to 6p21-23. Eur J Hum Genet 2000;8:986-90.

26 Erdemoglu AK, Akbostanci MC, Selcuki D. Familial cerebellar ataxia and hypogonadism associated with sensorimotor axonal polyneuropathy. Clin Neurol Neurosurg 2000;102:129-34.

27 Miller SA, Dykes DD, Polesky HF. A simple salting out procedure for extracting DNA from human nucleated cells. Nucleic Acids Res 1988;16:1215.

28 Cottingham RW Jr, Idury RM, Schaffer AA. Faster sequential genetic linkage computations. Am J Hum Genet 1993;53:252-63. 
29 Trokovic R, Trokovic N, Hernesniemi S, Pirvola U, Vogt Weisenhorn DM, Rossant J, McMahon AP, Wurst W, Partanen J. FGFR1 is independently required in both developing mid- and hindbrain for sustained response to isthmic signals. EMBO J 2003;22:1811-23.

30 van Swieten JC, Brusse E, de Graaf BM, Krieger E, van de Graaf R, de Koning I, Maat-Kievit A, Leegwater P, Dooijes D, Oostra BA, Heutink P. A mutation in the fibroblast growth factor 14 gene is associated with autosomal dominant cerebellar ataxia [corrected]. Am J Hum Genet 2003;72:191-9.

31 Pastore A, Tozzi G, Gaeta LM, Bertini E, Serafini V, Di Cesare S, Bonetto V, Casoni F, Carrozzo R, Federici G, Piemonte F. Actin glutathionylation increases in fibroblasts of patients with Friedreich's ataxia: a potential role in the pathogenesis of the disease. J Biol Chem 2003;278:42588-95.

32 Schulz JB, Lindenau J, Seyfried J, Dichgans J. Glutathione, oxidative stress and neurodegeneration. Eur J Biochem 2000:267:4904-11.

33 Nachmanoff DB, Segal RA, Dawson DM, Brown RB, De Girolami U. Hereditary ataxia with sensory neuronopathy: Biemond's ataxia. Neurology 1997;48:273-5.

34 Stevanin G, Durr A, Brice A. Spinocerebellar ataxias caused by polyglutamine expansions. Adv Exp Med Biol 2002;516:47-77.

35 Shoulders CC, Brett DJ, Bayliss JD, Narcisi TM, Jarmuz A, Grantham TT, Leoni PR, Bhattacharya S, Pease RJ, Cullen PM. Abetalipoproteinemia is caused by defects of the gene encoding the $97 \mathrm{kDa}$ subunit of a microsomal triglyceride transfer protein. Hum Mol Genet 1993;2:2109-16.

36 Lindenbaum J, Healton EB, Savage DG, Brust JC, Garrett TJ, Podell ER, Marcell PD Stabler SP, Allen RH. Neuropsychiatric disorders caused by cobalamin deficiency in the absence of anemia or macrocytosis. N Engl J Med 1988:318:1720-8

37 Steiner I, Kidron D, Soffer D, Wirguin I, Abramsky O. Sensory peripheral neuropathy of vitamin $\mathrm{B} 12$ deficiency: a primary demyelinating disease? J Neurol 1988;235:163-4

38 Hemmer B, Glocker FX, Schumacher M, Deuschl G, Lucking CH. Subacute combined degeneration: clinical, electrophysiological, and magnetic resonance imaging findings. J Neurol Neurosurg Psychiatry 1998;65:822-7.

39 Wilkinson PA, Crosby AH, Turner C, Patel H, Wood NW, Schapira AH, Warner TT. A clinical and genetic study of SPG5A linked autosomal recessive hereditary spastic paraplegia. Neurology 2003:61:235-8.

40 Ouahchi K, Arita M, Kayden H, Hentati F, Ben Hamida M, Sokol R, Arai H, Inove K, Mandel JL, Koenig M. Ataxia with isolated vitamin E deficiency is caused by mutations in the alpha-tocopherol transfer protein. Nat Genet 1995;9:141-5. 